Grand Valley State University

ScholarWorks@GVSU

$1-23-2017$

\title{
Students' Independent Use of Screencasts and Simulations to Construct Understanding of Solubility Concepts
}

Deborah Herrington

Grand Valley State University, herringd@gvsu.edu

Ryan D. Sweeder

Lyman Briggs College

Jessica VandenPlas

Grand Valley State University, vandenpj@gvsu.edu

Follow this and additional works at: https://scholarworks.gvsu.edu/chm_articles

Part of the Physical Sciences and Mathematics Commons

\section{ScholarWorks Citation}

Herrington, Deborah; Sweeder, Ryan D.; and VandenPlas, Jessica, "Students' Independent Use of Screencasts and Simulations to Construct Understanding of Solubility Concepts" (2017). Peer Reviewed Articles. 48.

https://scholarworks.gvsu.edu/chm_articles/48

This Article is brought to you for free and open access by the Chemistry Department at ScholarWorks@GVSU. It has been accepted for inclusion in Peer Reviewed Articles by an authorized administrator of ScholarWorks@GVSU.

For more information, please contact scholarworks@gvsu.edu. 


\title{
Students' Independent Use of Screencasts and Simulations to Construct Understanding of Solubility Concepts
}

\author{
Deborah G. Herrington ${ }^{1}$. Ryan D. Sweeder ${ }^{2}$. Jessica R. VandenPlas ${ }^{1}$
}

Published online: 23 January 2017

(C) Springer Science+Business Media New York 2017

\begin{abstract}
As students increasingly use online chemistry animations and simulations, it is becoming more important to understand how students independently engage with such materials and to develop a set of best practices for students' use of these resources outside of the classroom. Most of the literature examining students' use of animations and simulations has focused on classroom use with some studies suggesting that better outcomes are obtained when students use simulations with minimal guidance while others indicate the need for appropriate scaffolding. This study examined differences with respect to (1) student understanding of the concept of dissolution of ionic and covalent compounds in water and (2) student use of electronic resources when students were asked to complete an assignment either by manipulating a simulation on their own or by watching a screencast in which an expert manipulated the same simulation. Comparison of students' pre- and posttest scores, answers to assignment questions, near-transfer follow-up questions, and eye-tracking analysis suggested that students who viewed the screencast gained a better understanding of the dissolving process, including interactions with water at the particulate level, particularly for covalent compounds. Additionally, the eye tracking indicated that there were significant differences in the ways that the
\end{abstract}

Deborah G. Herrington

herringd@gvsu.edu

1 Grand Valley State University, Allendale, MI 49401, USA

2 Lyman Briggs College, Michigan State University, East Lansing, MI 48825, USA different treatment groups (screencast or simulation) used the electronic resources.

Keywords Simulation - Screencast · General chemistry · Solubility $\cdot$ Eye tracking

\section{Introduction}

Alex Johnstone's work (Johnstone 1982) suggesting that a deep, conceptual understanding of chemistry requires integration of knowledge on three levels (macroscopic, particulate, and symbolic) has arguably been one of the most influential ideas in chemistry education in the past 30 years (Taber 2013; Talanquer 2011). More recently, the use of particulate-level animations and simulations, which have an advantage over static representations as they can incorporate motion and trajectory, has been shown to improve student understanding of key chemistry concepts (Akaygun and Jones 2013). With the increased use of online, blended, and flipped learning environments, it is reasonable to expect these types of resources will see increased use as they can be easily accessed outside of class as course supplements or in online course modules for students to use as needed to support their learning. However, best practices for incorporating animations and simulations into online environments are likely to differ somewhat from best practices for their use in a classroom, particularly in cases where students are working alone without the benefit of an instructor or another student to point out salient aspects of the animation or simulation or to challenge a student's initial ideas. Therefore, this study aims to better understand how students interact with a particulate-level simulation or instructor-led screencast using this simulation to construct meaningful understanding of solution formation in an online learning environment. 


\section{Student Learning from Simulations}

Classroom instructors, who have a high level of expertise in chemistry, are generally able to easily switch between the three levels of representations (macroscopic, symbolic, and particulate), often without conscious thought, and are able to mentally transform chemical concepts from one form to another (Kozma et al. 1997). Students, on the other hand, have difficulty making connections among these three levels of representation, particularly at the particulate level (Chittleborough et al. 2007; Gabel et al. 1987; Nurrenbern and Pickering 1987; Sanger 2005; Williamson 2014), leading to an incomplete understanding of chemistry at the conceptual level (Gabel et al. 1987; Kozma et al. 1997; Wu et al. 2001). Dynamic animations and simulations can help students visualize phenomena and processes at the level of atoms and molecules, things we cannot physically observe and are not easily represented in static textbooks. For example, the motion and trajectory of particles as they interact with water in solution can be demonstrated in a simulation in a way that is difficult to convey through static images or verbal description alone. While both animations and simulations have been shown to enhance student mental models (Akaygun and Jones 2013; Sanger et al. 2001; Williamson and Abraham 1995; Yezierski and Birk 2006), simulations have the potential to actively engage the learners in the process by allowing them to enter or alter certain parameters.

The literature from the learning sciences, educational psychology, and cognitive psychology clearly demonstrates that students actively engaged in learning activities learn more than those in passive learning environments. This is consistent with the constructivist theory of learning in which learners construct understanding of concepts through their own experiences with the phenomena (von Glasersfeld 1993). Active construction of knowledge is notably more difficult than passively receiving information in a lecture or reading over a section in the textbook. Yet, it is this added difficulty that leads to deeper learning, helping the learner consolidate ideas and develop connections to other knowledge already stored in long-term memory (Brown et al. 2014). In fact, research shows that although rereading a text is one of the most common study strategies, it has little benefit for later retention of information (Callender and McDaniel 2009). On the other hand, struggling with solving a problem before being shown how to solve it results in better retention (Brown et al. 2014). This would seem to suggest that students interacting with simulations, as opposed to watching the simulation manipulated by someone else, would produce better learning outcomes.

Still, the use of animations and simulations as instructional tools brings with them their own set of difficulties. Students' abilities to develop, interpret, and use such models are not instinctive, but rather a skill that must be taught (Chittleborough et al. 2007). Though student use and understanding of these types of particulate-level models have been shown to result in deeper conceptual understanding, particulate representations can also result in difficulties and misconceptions, particularly for students with weak chemistry background. Animations have been shown to increase the number and type of misconceptions held by students, and there have been few significant conceptual gains shown for animation use over regular lecture (Sanger and Badger 2001; Sanger and Greenbowe 2000; Williamson and Abraham 1995). It is possible that novices in chemistry may not know how to attend to relevant details provided by an animation/simulation (Jones et al. 2005; Williamson and Abraham 1995) and therefore do not benefit from these resources as much as classroom instructors might hope. It is for this reason that some authors suggest supplementing student exposure to animations and simulations with additional materials, such as guided worksheets and assignments, or instructor questions (Jong and Van Joolingen 1998; Robinson 2000). Though several best practices have been developed for the use of animations and simulations as instructional materials in the classroom (Akaygun and Jones 2014; Chittleborough et al. 2007; Williamson 2014), little is known about how students use these resources on their own outside of a classroom environment. Additionally, some studies indicate greater learning gains for less guided exploration over more structured use of simulations (Adams et al. 2008; Akaygun and Jones 2013; Schwartz et al. 2013), where others have shown that allowing active control of simulations does not necessarily enhance student performance (Keehner et al. 2008). Instead, seeing the most task-relevant information improves performance, whether this is demonstrated by an expert or students find this information on their own (Keehner et al. 2008).

\section{Classroom vs. Online Learning}

Online learning environments provide both an opportunity and challenge for chemistry education. On the one hand, the flexibility of the online environment allows for on-demand instruction, where students can engage with the content when and where it is most convenient for them and for as long as needed (Keengwe and Kidd 2010). These environments allow us to reach students with time and geographic restrictions that make it difficult for them to attend face-to-face class meetings. However, despite the rapid increase in the use of online learning environments for complete or partial course 
content delivery, there have been few studies that examine the best practices in online learning with simulations (Grant and Thornton 2007) or how students use materials in online environments (Rutten et al. 2012). Studies examining students' use of simulations have largely taken place either in a classroom environment or in a structured laboratory situation where students interacted with other students and/or an instructor in completing tasks. In some cases, it was found that open exploration of such simulations in a classroom does not provide enough structure for students to obtain the maximum benefits from the simulations (Schwartz et al. 2013). Similarly, studies that examined students' use of simulations in physics indicated that students gained more from simulations when appropriate scaffolding was used to engage their attention and interaction (Adams 2010). There has been some work investigating the use of visualizations in online course modules, though again most of these modules were used in the classroom and often students worked in groups or pairs to complete the units (Chiu and Linn 2012). However, findings indicate that students often lack the selfregulation and metacognitive skills to construct understanding of concepts from open-ended environments and thus require appropriate supporting instruction, particularly prompts that require students to explain what they are observing in the visualization, to help them focus their attention on analyzing the important details of the visualization (Azevedo 2005; Chiu and Linn 2012; Gustafson et al. 2015). Furthermore, even with welldesigned instructional supports, students often still had difficulties making connections between representations (Chiu and Linn 2014; Gustafson et al. 2015).

Students using simulations on their own in an online environment should reasonably attain similar benefits in conceptual understanding of core chemistry concepts as using these simulations in the classroom. Though, providing appropriate scaffolding to direct students' attention to key elements of a simulation is likely to be even more important in an online environment as students will not have other students or an instructor to interact with or to monitor their use of the simulations. This is supported by research indicating that pedagogical considerations for instruction in an online environment are different from those in a face-to-face environment (Keengwe and Kidd 2010). Furthermore, many of these chemistry simulations incorporate multiple representations (particulate, macroscopic, symbolic, graphical, etc.) to help students see important connections between these representations; however, this greatly increases the complexity of the simulation environment, which may overwhelm students in the absence of appropriate scaffolding.

Given the rapidly increasing use of these materials in outof-classroom learning environments, it is important that we understand how students are using these resources and how we can make these resources more effective learning tools. Thus, this project investigated how active engagement with a simulation demonstrating solubility compares to the active viewing of a simulation manipulated by an expert in a screencast.

\section{Solutions and Solubility}

Understanding what happens at the particle level when ionic and covalent compounds dissolve in water has been found to be very challenging for students (Barke et al. 2009; Butts and Smith 1987; Liu and Lesniak 2006; Naah and Sanger 2012; Smith and Metz 1996). Research indicates several common student misconceptions relating to this process which include the following: (1) confusing the dissolving process with melting (Ebenezer and Erickson 1996; Liu and Lesniak 2006; Smith and Nakhleh 2011; Tien et al. 2007), (2) indicating that dissolved compounds react with or bond to water molecules (Ebenezer and Erickson 1996; Kelly and Jones 2007; Liu and Lesniak 2006; Smith and Nakhleh 2011; Tien et al. 2007), (3) showing ionic solids dissolving as neutral formula units/ionpairs (Butts and Smith 1987; Kelly and Jones 2007; Liu and Lesniak 2006; Smith and Nakhleh 2011; Smith and Metz 1996; Tien et al. 2007), and (4) believing that covalent bonds are broken during the dissolving process (Smith and Nakhleh 2011; Özmen et al. 2009). A recent study by Naah and Sanger (2013) investigated student understanding about dissolving of ionic compounds in relation to the type of representation used in the question (symbolic or particulate), the type of visualization used (static or animated pictures), and the representation order (symbolic questions before or after particulate representation). They found that students exhibited different misconceptions depending on the type of representation used in the question (particulate or symbolic), and that students performed better when looking at static pictures (before and after) of the dissolving process vs. watching an animation of the dissolving process. Though the authors suggest this indicates that dynamic depictions of chemical processes do not necessarily lead to better learning, it also may be the case that students are unable to interpret what they are seeing during the dissolving process without some guidance. This interpretation is consistent with a recent study by Kelly looking at students' mental models for conductivity of solid and aqueous sodium chloride before and after watching several animations (Kelly 2014). She reported that though many students were able to use the animations to identify deficiencies in their particulate-level drawings (mental models) and consequently revise their drawings, many students failed to recognize particular features of the animation or attended selectively to the particulars of the animation that they could use to 
rationalize their misconceptions. Given the difficulty students have with this concept and the previously documented misconceptions, the dissolving sugar and salt simulation from PhET Interactive Simulations was chosen for our initial investigation (PhET Interactive Simulations 2016).

\section{Research Questions}

Given that little is currently known about how screencasts or simulations can best be used to impact student learning of core chemistry concepts outside of the classroom environment, the goal of this study was to examine the following research questions:

1. What are the impacts of outside-of-class usage of simulations or screencasts on students' conceptual understanding of the solution process for ionic and covalent compounds?

2. How and where do students allocate attention while interacting with a simulation, as compared to a screencast, when coupled with a guided assignment?

\section{Methods}

\section{Simulation}

The sugar and salt solution simulation designed by the PhET Interactive Simulations project (PhET Interactive Simulations 2016) was chosen for this study. PhET simulations are designed to provide multiple representations, including at the particulate level, connect to the real world, and allow student interaction and inquiry (Lancaster et al. 2013). The sugar and salt simulation in particular contains three tabs for the learner to explore:

1. A macroscopic tab, in which one can test the conductivity of solutions after dissolving either salt or sugar in a tank of water. The user can control the amount of salt or sugar they add to the water, and the conductivity will change accordingly.

2. A microscopic tab, in which one can view the particlelevel behavior of a number of different solutes (sucrose, glucose, $\mathrm{NaCl}, \mathrm{CaCl}_{2}$, and $\mathrm{NaNO}_{3}$ ) when they are added to water. Primarily, the user observes that the ionic compounds separate into their component ions (e.g., $\mathrm{Na}^{+}$and $\mathrm{Cl}^{-}$ions separate when added to water) and the covalent compounds (e.g., sucrose) stay together as molecule when added to water. The water molecules are not shown here, only the solute particles.
3. A water tab, illustrating the particulate-level interactions between water molecules and a solute (either sugar molecules or sodium and chloride ions) when that solute is dissolved in water.

\section{Assignment Design}

Using the backward design (Wiggins and McTighe 2005) approach outlined in Fig. 1, the following key learning objectives related to the dissolving of ionic and covalent compounds in water were identified:

1. Explain that when ionic compounds dissolve in water, they dissociate into ions, which causes the solution to conduct electricity

2. Explain that when covalent compounds dissolve in water, the molecules remain intact, which does not allow the solution to conduct electricity

3. Describe how ionic and covalent compounds interact with water during the dissolution process

Short, matched pre- and posttests to assess student knowledge of these learning objectives were then developed. Five questions were generated for each test, aligned with identified prerequisite knowledge and learning objectives, and consistent with literature-identified misconceptions or common student errors seen by the instructors. Additionally, three followup questions which required students to apply what they had learned from engaging with this simulation/watching the screencast to near-transfer tasks were included as part of the assignments. The follow-up questions required students to draw particulate-level representations of ionic and covalent compounds, including their interactions with water, that were not observable using the simulation and use those drawings to explain which compounds would conduct electricity when dissolved in water.

This was followed by the development of a set of instructions to guide students' interactions with the simulation, which included embedded questions to focus students on the salient aspects of the simulation and help them construct an understanding of how the dissolving of ionic compounds in water differs from that of covalent compounds. The assignment was reviewed by two undergraduate research students and one external chemistry instructor and revised accordingly based on their feedback.

Finally, the revised assignment served as a script to create a screencast that introduced students to the same basics of the simulation (PHET Screencast Solubility of Ionic Compounds 2015). The 6-min-long screencast was narrated by an instructor who was not familiar to the students in the study. Students viewing the screencast answer the same or very similar 
Fig. 1 Backward design used for assignment and screencast creation

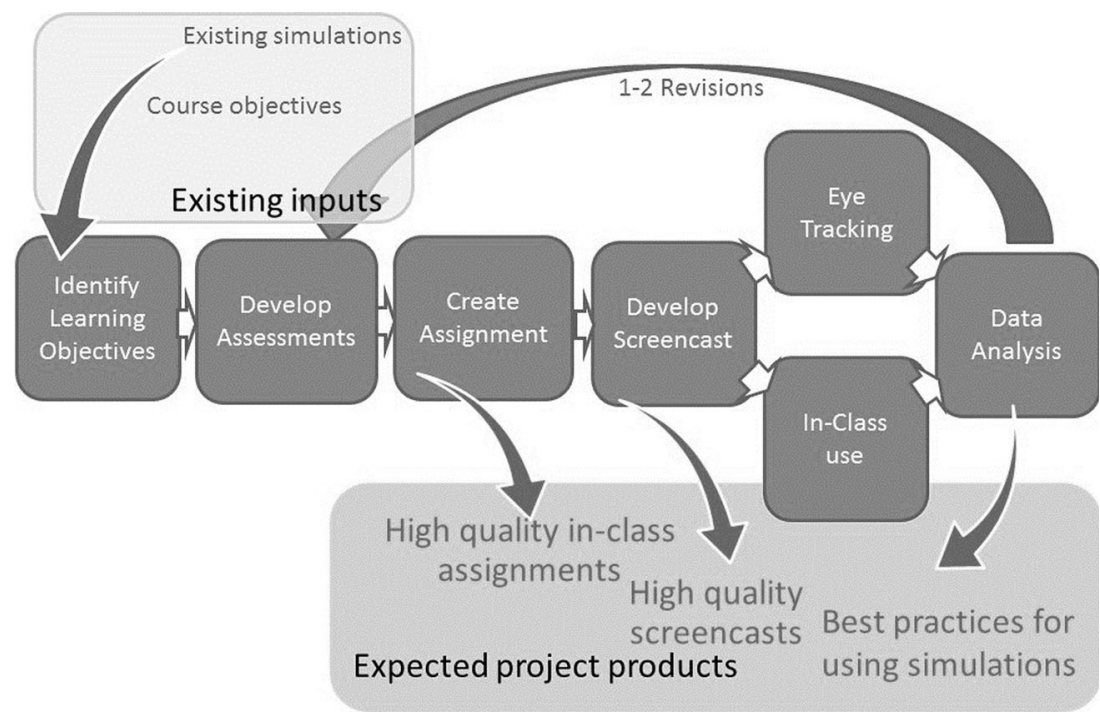

questions to students using the simulation to provide a matched experience. Accordingly, we initially try and limit the screencast narration to highlighting direct observations from the simulation and in general do not go into deeper descriptions of concepts to ensure that students viewing the screencast are still required to construct their own understanding of core concepts. Further, as the assignment only took students through the examination of what happened when sodium chloride and sucrose dissolved in water, both groups were encouraged to explore the other compounds available in the simulation on their own.

\section{Classroom Study: Participants and Study Design}

The participants in this study were 239 students enrolled in one of four 2nd semester introductory chemistry lecture sections taught by two different instructors at a large, public institution in the Midwest region of the USA. Each instructor taught two lecture sections. Prior to this, all students had received previous instruction about covalent and ionic bonding, but this assignment was to serve as the introduction to the solution unit. Students first completed an in-class pretest and were then given an assignment, including follow-up questions, to complete outside of class. Two lecture sections, one from each instructor, were given an assignment that required them to work through the sugar and salt solution PhET simulation on their own with appropriate scaffolding $(n=110)$. The other two sections completed the assignment while watching a screencast where an instructor led students through the simulation $(n=129)$. During the next class meeting, the assignments were collected and students completed a matched posttest. Students then received instruction on the topic of solubility, which built on their experiences with the simulation/screencast.
To determine how students' conceptual understanding of the solution process changed and to identify any differences in changes between the screencast and simulation groups, a variety of statistical analyses were completed using the Statistical Package for the Social Sciences (SPSS) (IBM Corp. 2013). For the students' pre- and posttest results, the students' scores were initially evaluated for equivalency using an analysis of variance (ANOVA) test. Given the high level of success on the pretest, normalized change scores were calculated (Marx and Cummings 2007). To statistically analyze the qualitative responses, we employed a $z$-test of proportions to identify differences in the distribution of the coded student responses. To ascertain whether there was a treatment effect and if the treatment effect disproportionately impacted either student with high or low prior knowledge, student responses were coded into dummy variables. We then used linear regression models to see how much of the posttest score variance could be explained by pretest score, treatment, and a cross product of pretest and treatment as independent variables.

A qualitative analysis of student responses to the assignment and follow-up questions was used to identify any differences in student understanding as a result of the different interventions. Consistent with the constructivist perspective of learning in which learners construct understanding from their experiences, in analyzing the student responses that required written answers, we used open coding for one instructor's two classes of students to identify common patterns in student responses. We then used a constant comparative approach for the second instructor's classes to ensure that our codes encompassed all of the possible responses in our sample (Strauss and Corbin 1990). Answers to most of these questions were straightforward, with students in both groups (simulation and screencast) providing very similar and correct answers. However, there were two questions with notable 
differences, so subsequent analysis focused primarily on these questions.

For the follow-up question requiring students to draw particulate-level representations of ionic and covalent compounds dissolved in water, we used a set of a priori codes based on the key elements in a particulate-level diagram that would demonstrate understanding of the dissolving process as described in the learning objectives as well as elements in a particulate-level diagram that would demonstrate naïve ideas as identified in the research literature (Miles and Huberman 1994). For example, for methanol, we looked at whether the methanol molecules were kept intact or whether they were split apart into atoms or ions. For compounds like $\mathrm{CaSO}_{4}$, which contain polyatomic ions, we looked at whether drawings showed the polyatomic ions kept as a unit or broken apart, or if the ionic compound was treated like a molecule and the whole thing was kept together. Additionally, as students were explicitly asked to show how water interacts with the dissolved particles, we also coded whether students (1) included water molecules in their drawings and (2) correctly oriented the water molecules. Based on this analysis, we identified divergent answers for the two compounds $\left(\mathrm{CH}_{3} \mathrm{OH}\right.$ and $\mathrm{CaSO}_{4}$ ) which were not depicted in the simulation. Finally, students were asked to identify which of the compounds they were asked to draw particulate-level pictures for $\left(\mathrm{CaCl}_{2}\right.$, $\mathrm{NaNO}_{3}, \mathrm{CaSO}_{4}$, and $\mathrm{CH}_{3} \mathrm{OH}$ ) would conduct electricity when dissolved in water and to explain why they thought these would conduct electricity. Analysis of these questions looked at (1) which compounds students identified as electrolytes, (2) students' reasoning regarding what made something an electrolyte, and (3) whether or not their identification of electrolytes and their reasoning were consistent with their drawings. Interrater reliability for the coding was established by two raters independently coding all of the written answers and diagrams, comparing their coding, and then negotiating until $100 \%$ agreement was obtained.

\section{Eye-Tracking Study}

In order to investigate how students interact with online resources such as simulations and screencasts, many researchers have turned to the use of eye-tracking technology (Boucheix and Lowe 2010; Chuang and Liu 2012; de Koning et al. 2010; Hyönä 2010; Schmidt-Weigand et al. 2010). Eye tracking allows researchers to follow an individual's eye movements, which are considered to be a measure of overt visual attention; that is, where an individual's eyes are focused is also considered to be the focus of their mental processing (Just and Carpenter 1980).

To address research question 2 and investigate how students allocate their attention between the assignment and the different resources (simulation or screencast), 12 student volunteers were recruited to participate in eye-tracking interviews. This sample size is consistent with previously published eye-tracking studies in the field of chemistry education, which range from 9 to 28 participants per study, and average 16 participants per study (Havanki and VandenPlas 2014). These students were recruited from lecture sections that did not participate in the larger classroom study, but who had covered the relevant prerequisite chemistry content. During the interviews, participants engaged in activities that paralleled the classroom study outline, but in a condensed timeframe. They first took the pretest using paper and pencil to determine their prior knowledge on the topic and then completed either the screencast $(n=7)$ or simulation $(n=5)$ assignment, answering all questions embedded in the activity, while seated at a Tobii T60 eye-tracking system. This system displays a stimulus on a 17-in. computer monitor and samples the participant's eye position at a rate of $60 \mathrm{~Hz}$. Participants sat approximately $24 \mathrm{in}$. from the monitor, and the system was calibrated to each participant before data collection began. For the eye-tracking portion of the interviews, students were shown a split screen, with the simulation/screencast occupying the top half of the screen and the corresponding assignment displayed as a pdf document on the bottom half (see Fig. 2). They were given control of the mouse and could control the simulation or pause/rewind the screencast as needed. They were also able to scroll through the assignment questions and were asked to give all answers aloud to avoid the need for writing. All responses were recorded by a research assistant. After working through this assignment, participants completed the follow-up assignment using paper and pencil. Compared to the classroom study, the only change to the sequence of events was with the posttest questions. Students engaged in the classroom study typically responded to posttest questions 24-72 $\mathrm{h}$ after completing the activity. As this was not possible for students participating in the eye-tracking study, students were given the opportunity to edit their answers to any pretest responses they chose, which was used as a measure of how their thinking changed as a result of the intervention. These sessions lasted approximately $30 \mathrm{~min}$ each.

The eye-tracking data were processed to identify fixations using the Tobii fixation filter (Tobii Technology 2016), which detects changes in eye position using a sliding average method. This method uses a window size of five data points and identifies differences in eye position greater than 35 pixels between windows. Successive gaze points that fall under this threshold are collapsed into a single fixation. A fixation is an eye movement in which the eye is relatively still and during which the eye is focused and mental processing is assumed to take place (Holmqvist et al. 2011). During reading and visual search tasks, eye fixations tend to be in the range of 200 $300 \mathrm{~ms}$ (Holmqvist et al. 2011). In this study, fixations were identified by location as being either on the electronic resource (simulation or screencast) or on the on-screen assignment. The 
Fig. 2 Stimulus presentation for eye-tracking study, showing simulation at the top of the screen and assignment at the bottom of the screen

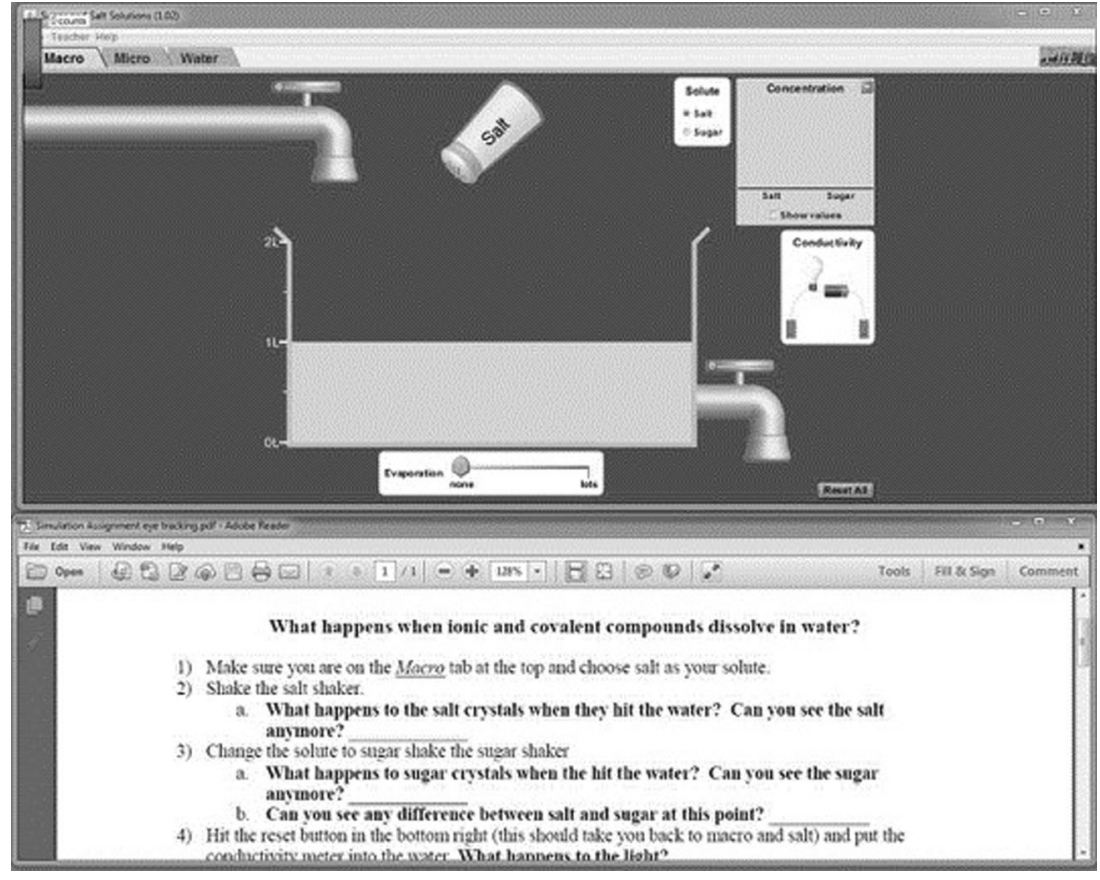

total fixation time (in seconds) and number of fixations within each of these two areas of interest (AOIs) were measured. Mixed between-within subject ANOVAs were used to analyze the data. For these models, fixation time and number of fixations were used as dependent variables with treatment (simulation or screencast) as a between-subject variable. Fixation time was used as a measure of attention allocation; the more time an individual spends fixating on an object, the more attention they have paid to this object (Goldberg and Kotval 1999; Holmqvist et al. 2011). The number of fixations made by an individual can be also used as a measure of attentional focus. In general, a high number of fixations have been shown to correlate both with a low level of expertise and a low level of search efficiency (Goldberg and Kotval 1999). A high number of fixations may also indicate an unfocused individual, who is spreading their attention over a number of objects indiscriminately.

\section{Results}

In general, analysis of students' responses to assignment questions suggests that most students, regardless of treatment, were able to identify that the key difference between the dissolving of $\mathrm{NaCl}$ (salt) and sugar (sucrose) is that salt dissociates into ions when it dissolves in water whereas sugar stays together as a neutral molecule (learning objectives (LO) 1 and 2 ). However, detailed analysis of the follow-up questions suggests that overall, the students who viewed the screencast were better able to (1) identify electrolytes and explain what caused something to be an electrolyte, (2) identify how water interacts with covalent compounds during the dissolving process, and (3) correctly depict what would happen at the particulate level when methanol $\left(\mathrm{CH}_{3} \mathrm{OH}\right)$ dissolves in water. Moreover, the eye-tracking studies indicate statistically significant differences in how students allocate their attention to the electronic resource (simulation or screencast) depending on the treatment. The following sections discuss these results in detail as they pertain to the research questions guiding the study.

\section{Pre- and Posttest Analyses}

The pre- and posttest scores provided one measure for determining how students' understanding of solubility changes as a result of completing the out-of-class assignment as well as identifying potential differences between the two treatments (research question 1). The pre- and posttests each had a series of five questions that were matched based on content. The pretest highlighted that there were no statistical differences between the four sections tested on either the mean scores (simulation $2.89 \pm 1.11$; screencast $3.06 \pm 1.20$; ANOVA $F_{1,237}=1.29, p=0.258$ ) or via a $z$-test of proportions to examine the distribution of scores. This was also the case when examining the differences between instructors. This reaffirmed the supposition that there was no statistical difference between the sections initially. Paired $t$ tests for the preand posttests indicated that the simulation group did not show significant difference between the assessments (change of $0.02 \pm 1.47, p=0.897$ ) whereas the screencast group showed a statistically significant increase from pre- to posttest $(0.28 \pm 1.43, p=0.028)$. However, comparison of normalized change scores (simulation $0.06 \pm 0.53$; screencast $0.16 \pm 0.52$; 
ANOVA $F_{1,220}=2.30, p=0.131$ ) showed nonsignificant differences between the two treatments. To further examine possible differences between the two treatment groups, we used a multiple line regression model to determine how much of the variance of the posttest score could be explained by the pretest score, treatment, and instructor. The best model was able to statistically explain $12.5 \%$ of the variance of posttest score. The pretest explained $11 \%$ of the variance and the treatment method explained an additional $1.5 \%$, indicating that the students using the screencast outperformed those with the simulation (based on the positive beta value) but that the treatment only explained a small amount of variance. The instructor provided no additional predictive value. Similarly, adding in a cross product to test for interaction effects between the treatment and pretest score had no additional predictive power. This may not be surprising given the very coarse measure provided by a five-question test.

However, an examination of the individual questions of the posttest identified some differences in understanding between groups. Much of the gain by the screencast group arose from a single question that asked what species were present when $\mathrm{CO}_{2}$ dissolves in water. A statistically larger percent of the screencast students (55\%) correctly identified $\mathrm{CO}_{2}$ (aq) as the answer compared to the simulation group (35\%) $\left(X^{2}=10.05, p<0.01\right)$, whereas the groups were at an identical percent on the corresponding pretest question. The incorrect students indicated that $\mathrm{CO}_{2}$ would break into ions. This suggests that the screencast may more effectively direct student attention to the relevant details for the solubility of molecular compounds.

\section{Assignment and Follow-up Question Analyses}

The difference in understanding about molecular solubility was supported by examining students' responses to follow-up questions asking them to draw particulatelevel representations of what happened when $\mathrm{CaSO}_{4}$ and $\mathrm{CH}_{3} \mathrm{OH}$ (both compounds not found in the simulation) dissolved in water. Responses suggested that there were differences in understanding not fully captured in the preand posttest analyses. Each student drawing was analyzed as to how the particles were separated, the inclusion of water molecules, and the orientation of the water molecules. From this, we found that the screencast students had more success on all of the learning objectives. With respect to LO 1 (explain that ionic compounds separate into ions when dissolved in water and this results in a conductive solution), an independent sample $t$ test indicated that students who viewed the screencast were better able to answer the follow-up assignment questions that asked them to explain why compounds were electrolytes in solution (Fig. 3a) $(p=0.042)$. Similar to a previous study looking at students' use of simulations (Liu et al. 2008), what was more striking was that this success seemed highly dependent on student prior knowledge, as measured by pretest scores (Fig. 3b). Further, student drawings of methanol dissolved in water indicated that the screencast students also had a better understanding that when covalent compounds dissolve in water, they stay together as molecules (LO 2). In analyzing the drawings made by students who interacted with the simulation, $23 \%$ showed methanol molecules broken apart into atoms or ions, as compared to only $11 \%$ of the screencast students, statistically different via a $z$-test of proportions (see Fig. 4 for sample drawing). A more accurate understanding of how molecular compounds solubilize by screencast students is consistent with the pre/post analyses indicating that the screencast students scored significantly higher on the posttest question related to the dissolving of $\mathrm{CO}_{2}$ in water.

Evidence for better success on LO 3 (describe how the interactions between compounds and water during the dissolution process) came from the question where students were asked to: "Draw a picture in the space below of 4 units of $\mathrm{CaSO}_{4}\left[\mathrm{CH}_{3} \mathrm{OH}\right]$ dissolved in water. Be sure to show how the water interacts with the dissolved particles and provide a key where necessary." Examination of the drawings showed notable differences in how the students perceived the water. Screencast students showed statistically higher rate of including the proper orientation in their drawings ( 28.0 vs. $8.7 \%$, $p<0.05$; Fig. 5) and were more likely to include the water in the drawing $(64.5$ vs. $44.6 \%, p<0.05)$. These results are consistent with student answers to the assignment question associated with the water tab for the simulation. After being asked to consider how the water molecules interacted with each other and how the water molecules interacted with the $\mathrm{Na}^{+}$and $\mathrm{Cl}^{-}$ions, which all students from both treatment groups correctly indicated that the positive dipole of water interacted with the negative dipole of another water molecule or the $\mathrm{Cl}^{-}$ion, students were asked "How does the behavior of sugar in water differ from the salt?" In response to this question, the majority of students from both groups (Fig. 6) indicated that sugar molecules stayed together while salt separated into ions. However, for the students that also mentioned an interaction with water, there was a notable difference between the responses from the screencast and simulation students. Most of the screencast students $(85 \%)$ indicated that there were interactions between water and sucrose similar to those between two water molecules. For the simulation students, on the other hand, $88 \%$ primarily indicated that the difference was that there were no interactions or indiscriminate interactions (both coded as no interactions) between water and the sucrose. Moreover, it appears that the students who explicitly stated the interaction between water and sucrose were better able to 
Fig. 3 Students providing correct answer to the follow-up question "Explain why you think [student identified] substances will conduct electricity when dissolved in water." a All students. b Separated based on pretest score. Asterisk indicates statistical significance

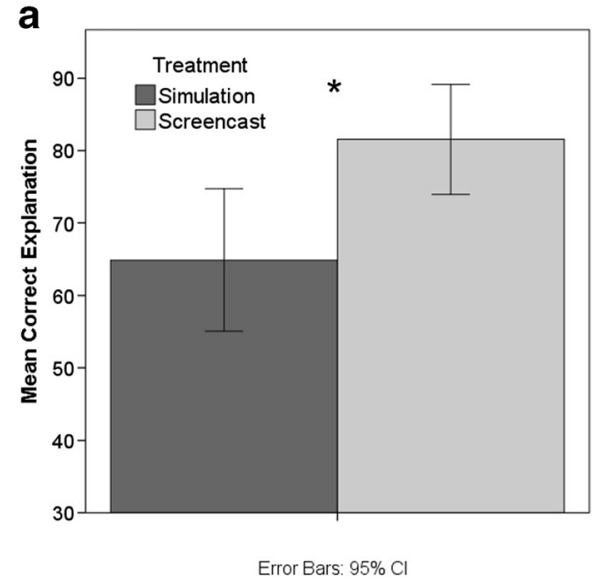

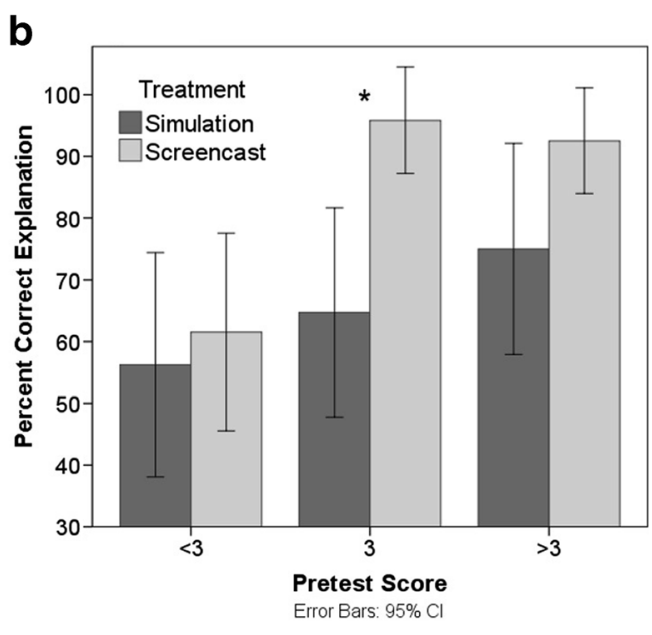

correctly orient water around methanol molecules in their follow-up drawings ( 45 vs. $14 \%$ of students not mentioning water).

\section{Eye-Tracking Analysis}

In addressing our second research question (how and where do students allocate attention while interacting with a simulation, as compared to a screencast, when coupled with a guided assignment?), we found that there were significant differences in how the different groups (screencast and simulation) interacted with the materials. Mean fixation times and number of fixations for each treatment group are given in Table 1. The number of fixations and total fixation time were found to be significantly correlated for both the resource and the assignment $(r=0.92, p<0.001$ for both). This is consistent with the results of other eye-tracking studies on student problem solving in chemistry education (Stieff et al. 2011; Tang et al. 2016). For this reason, the remainder of the analysis focuses on fixation time alone.

A mixed-method ANOVA with fixation time as the dependent variable was conducted to investigate the impact of treatment on the division of attention between assignment and resource. Preliminary assumption testing was

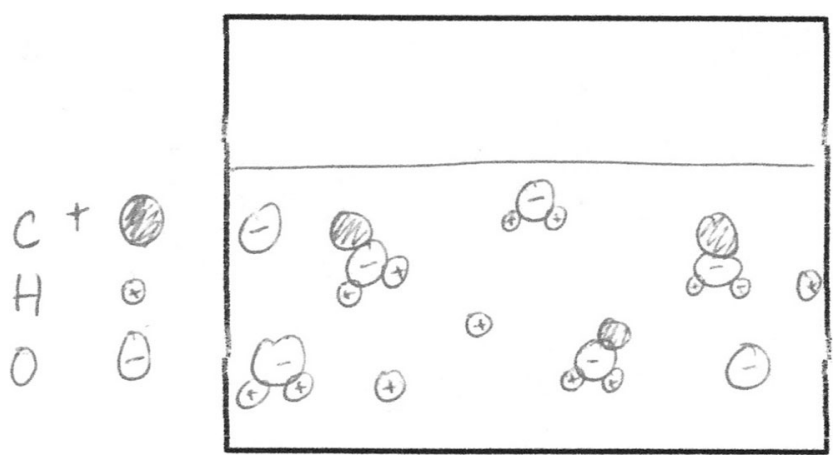

Fig. 4 Simulation student drawing of methanol in water conducted to check for univariate normality, linearity, univariate and multivariate outliers, homogeneity of variancecovariance matrices, multicollinearity, and equality of error variances, with no violations observed. Despite the small sample size, this suggests that the data meet all assumptions for a mixed-method ANOVA. This test found significant main effects for both the AOI (assignment or resource, $\left.F_{1,10}=5.00, p=0.049\right)$ and the interaction effect between treatment and AOI $\left(F_{1,10}=7.22, p=0.023\right)$. In the presence of a significant interaction effect, the main effect for AOI was not probed further. To investigate the significant interaction effect, tests of simple main effects were conducted using a Bonferroni adjustment to correct for multiple comparisons. This test showed that there was no significant difference $\left(F_{1,10}=0.046, p=0.834\right)$ in the amount of time that participants spent fixating on the assignment, yet there was a statistically significant difference $\left(F_{1,10}=5.88, p=0.036\right)$ in fixation time on the electronic

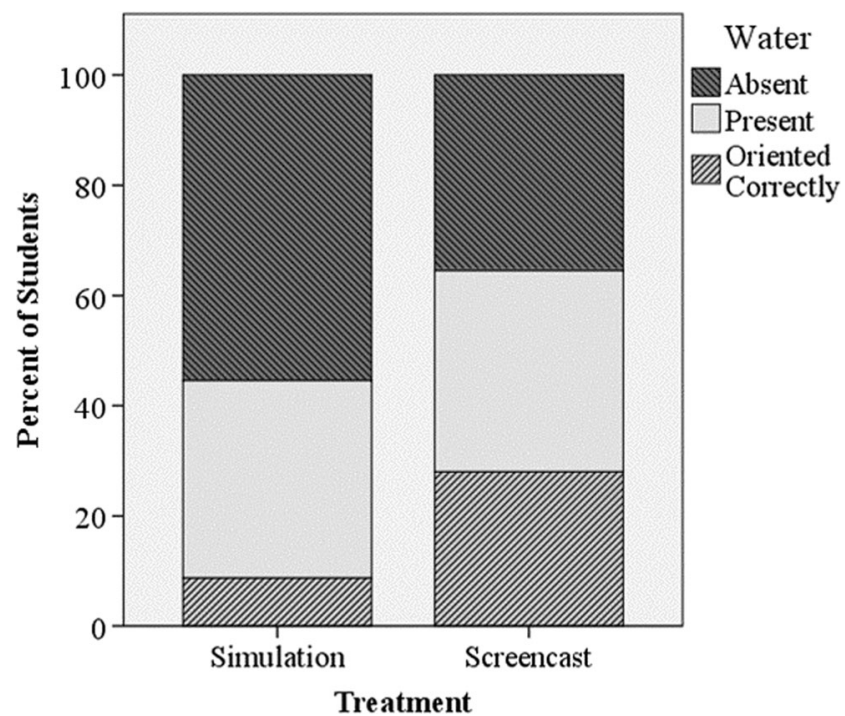

Fig. 5 Students' depiction of water in drawings of dissolved compounds 
Fig. 6 Frequency of student responses to question about how sugar and salt differ with respect to their interactions with water as they dissolve

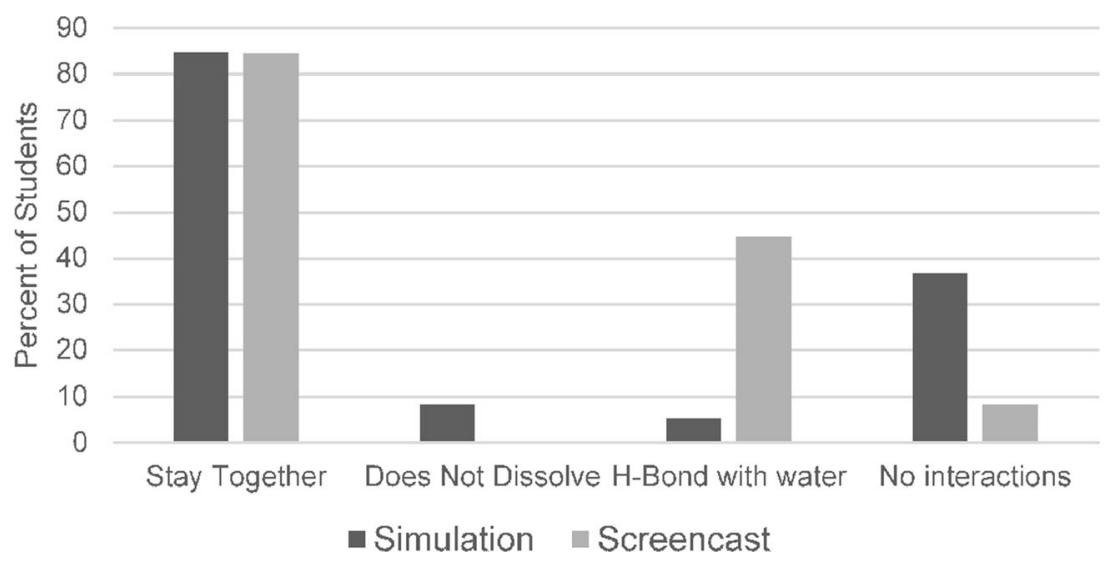

resource itself (see Table 1). This difference suggests that participants were equally engaged with the assignments they were given but, in the case of the screencast group, spent significantly more time focusing on the electronic resource.

\section{Discussion}

The results from this work provide useful insights into how we might best use simulations in online learning environments. Although simulations provide the benefit of allowing students to actively engage through manipulation of variables, this work demonstrates that even with guided facilitation designed to direct student attention to the salient aspects of the simulation, the students who only engaged with the simulation were less likely to observe key interactions or identify key relationships, such as molecular compounds staying intact as molecule or the ways in which water interacts with molecular compounds. The students who watched a screencast of an expert manipulating the simulation and directing students' attention to the important interactions and elements demonstrated an increased understanding of the dissolution process and how water interacts with these compounds during dissolution, particularly for covalent compounds. Moreover, these students were better able to apply their knowledge to near-transfer tasks. The eye-tracking study provides some ability to posit a mechanism by which the screencast has its impact. Though the students spend equal time engaged with the assignment questions, regardless of treatment, students in the screencast treatment spent significantly more time looking at the electronic resource than students who interact with the simulation. Though the screencast may be improving student performance through a simple time-on-task effect, in which screencast students spend more time engaged with the topic than simulation students, given that the electronic resource is where students can visualize the key particle-level interactions, it is also likely that the screencast students gain a better understanding of the particle-level behavior because they spend more time focusing on these interactions than the simulation students did. Furthermore, it is possible that the verbal narration of the screencast also helps draw student attention and improves their understanding. In previous studies, verbal narration with multimedia presentations was shown to result in better student performance when compared to only onscreen presentations (Mayer and Moreno 1998). This could be explained by dual-coding theory which suggests a person can encode information both visually and auditorily, and using both of those channels over just one improves a person's ability to recall the information (Mayer and Sims 1994; Paivio 1991). Additionally, it has been shown that students who are given verbal directions before engaging with a multimedia presentation derive a greater benefit from the presentation, suggesting that the expert narration included in the screencast may be improving performance by priming students to attend to relevant cues within the simulation before they address the assignment and follow-up questions (Canham and Hegarty 2010). For example, on the very busy images of water molecules interacting with the solute, the screencast appears to help focus students on the evidence that water does indeed have a preferred orientation around the sucrose molecule (which students are more capable of extrapolating to methanol in the
Table 1 Fixation time and number of fixations by treatment

\begin{tabular}{llllll}
\hline Treatment & \multicolumn{2}{l}{ Fixation time (s) mean (std. dev.) } & & \multicolumn{2}{l}{ Number of fixations mean (std. dev.) } \\
\cline { 2 - 3 } & Resource & Assignment & & Resource & Assignment \\
\hline Simulation $(n=5)$ & $203(57)$ & $213(50)$ & & $459(156)$ & $767(149)$ \\
Screencast $(n=7)$ & $311(86)$ & $206(56)$ & & $730(230)$ & $708(160)$ \\
\hline
\end{tabular}


transfer task). The students engaging with the simulation may simply not be able to identify the pattern as readily. This mechanism supports the idea that the screencast effectively reduces the cognitive load for the students.

\section{Implications for Teaching}

Earlier studies conducted on students viewing particulatelevel animations demonstrated that students gain the most from such animations when they are integrated into a classroom presentation that includes instructor narration (Burke et al. 1998; Kozma et al. 1997; Mayer and Anderson 1991; Mayer and Anderson 1992). The current study suggests that this may also be true of simulations. Although simulations provide a rich environment that allows for student-directed exploration, even written instructions that try to scaffold students' use of the simulation may not effectively direct students' attention to all the salient features to facilitate student learning. Screencasts that provide an introduction to the simulation and highlight key features are one way to provide this context in the absence of classroom instruction. Instructors who wish to incorporate simulation use into a laboratory, classroom, or homework environment should properly orient students to the simulation before free exploration. In a distance learning or flipped classroom, screencasts can be used to provide this valuable orientation. However, care should be taken not to simply provide students with answers in the screencast, which can shortchange student learning by removing the opportunity for authentic inquiry and exploration by simply becoming another lecture delivery tool; screencasts should instead highlight features, such as the use of control panels, the significance of included graphs or numerical displays, and the meaning or importance of multiple representations intended to convey chemical information.

Furthermore, in assessing student learning from these experiences, it is important to focus on both students' understanding of the key ideas from the simulation and their abilities to transfer that knowledge to situations not directly explored in the simulation. In particular, if designing screencasts or assignments to scaffold students' use of simulations, questions pertaining to the key ideas of the simulation can help instructors identify areas of confusion so that they can make appropriate modifications to the screencast or the scaffolding instructions to address these problems. For example, in our case, it was challenging for students using the simulation to accurately interpret how the water molecules interact with the sucrose molecules. Therefore, in planning to use this assignment in the future, we have added some additional instructions to try and help students better attend to these interactions. Additionally, we found that the near-transfer questions that required students to draw pictures and explain provided the most insight into differences in student understanding of the dissolution process. In view of this, for subsequent classes, we have modified our pretest assignment to use these types of questions and are using the follow-up questions as the postassessment.

\section{Conclusions}

For the sugar and salt solution PhET simulation, students who completed an assignment and follow-up questions by viewing an expert-led screencast demonstrated greater understanding of how molecular compounds interact with water compared to students who completed a matched assignment by working through guided manipulations of the simulation on their own. The eye tracking suggests that this improvement may be a result of greater interaction with the electronic resource. However, it is also likely that this improved understanding is derived from the dual coding made possible by the verbal narration of the screencasts and the ability of the screencast to focus student attention on salient details of the simulation. This work also reaffirms the superiority of constructed responses on transfer questions over short multiple-choice preand posttests for identifying changes in student understanding of challenging concepts.

Acknowledgements The authors would like to recognize contributions to this work by Dena Warren, Karli Gormley, Marissa Biesbrock, Kristina Pacelli, Stephanie Lerchenfelt, and Treyce Sanderson. Ryan Sweeder would also like to thank the Lyman Briggs Trajectory Fund for financial support for this work.

Compliance with Ethical Standards This study has been approved as exempt by the GVSU and MSU Institutional Review Boards: Exempt Reference no. GVSU: 15-079-H and 16-012-H; MSU: x15-775e.

All procedures performed in studies involving human participants were in accordance with the ethical standards of the institutional and/or national research committee and with the 1964 Helsinki Declaration and its later amendments or comparable ethical standards.

\section{References}

Adams WK (2010) Student engagement and learning with PhET interactive simulations. Il Nuovo Cimento C 33(3):21-32

Adams WK, Paulson A, Wieman CE (2008) What levels of guidance promote engaged exploration with interactive simulations? AIP Conference Proceedings 1064(1):59

Akaygun S, Jones LL (2013) Animation or simulation: investigating the importance of interactivity for learning solubility equilibria. In: Suits JP, Sanger MJ (eds) Pedagogic roles of animations and simulations in chemistry courses, vol 1142, pp 127-159

Akaygun S, Jones LL (2014) Words or pictures: a comparison of written and pictorial explanations of physical and chemical equilibria. Int J Sci Educ 36(5):783-807

Azevedo R (2005) Using hypermedia as a metacognitive tool for enhancing student learning? The role of self-regulated learning. Educ Psychol 40(4):199-209 
Barke H-D, Hazari A, Yitbarek S (2009) Misconceptions in chemistry: addressing perceptions in chemical education. Springer, Berlin

Boucheix J-M, Lowe RK (2010) An eye tracking comparison of external pointing cues and internal continuous cues in learning with complex animations. Learn Instr 20(2):123-135

Brown PC, Roediger HL, McDaniel MA (2014) Make it stick: the science of successful learning. Belknap Press of Harvard University Press, Cambridge, MA

Burke KA, Greenbowe TJ, Windschitl MA (1998) Developing and using conceptual computer animations for chemistry instruction. J Chem Educ 75(12):1658-1661

Butts B, Smith R (1987) HSC chemistry students' understanding of the structure and properties of molecular and ionic compounds. Res Sci Educ 17(1):192-201

Callender AA, McDaniel MA (2009) The limited benefits of rereading educational texts. Contemp Educ Psychol 34(1):30-41

Canham M, Hegarty M (2010) Effects of knowledge and display design on comprehension of complex graphics. Learn Instr 20(2):155-166

Chittleborough GD, Mocerino M, Treagust DF (2007) Achieving greater feedback and flexibility using online pre-laboratory exercises with non-major chemistry students. J Chem Educ 84(5):884-888

Chiu JL, Linn MC (2012) The role of self-monitoring in learning chemistry with dynamic visualizations. In: Zohar A, Dori YJ (eds) Metacognition in science education, vol 40, pp. 133-163

Chiu JL, Linn MC (2014) Supporting knowledge integration in chemistry with a visualization-enhanced inquiry unit. J Sci Educ Technol 23(1):37-58

Chuang H-H, Liu H-C (2012) Effects of different multimedia presentations on viewers' information-processing activities measured by eye-tracking technology. J Sci Educ Technol 21(2):276-286

de Koning BB, Tabbers HK, Rikers RM, Paas F (2010) Attention guidance in learning from a complex animation: seeing is understanding? Learn Instr 20(2):111-122

Ebenezer JV, Erickson GL (1996) Chemistry students' conceptions of solubility: a phenomenography. Sci Educ 80(2):181-201

Gabel DL, Samuel KV, Hunn D (1987) Understanding the particulate nature of matter. J Chem Educ 64(8):695-697

Goldberg JH, Kotval XP (1999) Computer interface evaluation using eye movements: methods and constructs. Int J Ind Ergon 24(6):631-645

Grant MR, Thornton HR (2007) Best practices in undergraduate adultcentered online learning: mechanisms for course design and delivery. MERLOT J Online Learn Teach 3(4):346-356

Gustafson B, Mahaffy P, Martin B (2015) Guiding age 10-11 students to notice the salient features of physical change models in chemistry digital learning objects. J Comp Math Sci Teach 34(1):5-39

Havanki KL, VandenPlas JR (2014) Eye tracking methodology for chemistry education research. In: Bunce DM, Cole RS (eds) Tools of chemistry education research. American Chemical Society, Washington, DC, pp 191-218

Holmqvist K, Nyström M, Andersson R, Dewhurst R, Jarodzka H, Van de Weijer J (2011) Eye tracking: a comprehensive guide to methods and measures. Oxford University Press, Oxford

Hyönä J (2010) The use of eye movements in the study of multimedia learning. Learn Instr 20(2):172-176

IBM Corp (2013) IBM SPSS statistics for Windows (version 23.0). IBM Corp, Armonk, NY

Johnstone AH (1982) Macro- and micro-chemistry. Sch Sci Rev 64:377-379

Jones LL, Jordan KD, Stillings NA (2005) Molecular visualization in chemistry education: the role of multidisciplinary collaboration. Chemistry Education Research and Practice 6:136-149

Jong TD, Van Joolingen WR (1998) Scientific discovery learning with computer simulations of conceptual domains. Rev Educ Res 68(2):179-201

Just MA, Carpenter PA (1980) A theory of reading: from eye fixations to comprehension. Psychol Rev 87(4):329-354
Keehner M, Hegarty M, Cohen C, Khooshabeh P, Montello DR (2008) Spatial reasoning with external visualizations: what matters is what you see, not whether you interact. Cogn Sci 32:1099-1132

Keengwe J, Kidd TT (2010) Towards best practices in online learning and teaching in higher education. Journal of Online Learning and Teaching 6(2):533-541

Kelly RM (2014) Using variation theory with metacognitive monitoring to develop insights into how students learn from molecular visualizations. J Chem Educ 91(8):1152-1161

Kelly RM, Jones LL (2007) Exploring how different features of animations of sodium chloride dissolution affect students' explanations. J Sci Educ Technol 16(5):413-429

Kozma RB, Russell JW, Jones T, Wykoff J, Marx N, Davis J (1997) Use of simultaneous-synchronized macroscopic, microscopic, and symbolic representations to enhance the teaching and learning of chemical concepts. J Chem Educ 74(3):330-334

Lancaster K, Moore EB, Parson R, Perkins KK (2013) Insights from using $\mathrm{PhET}$ 's design principles for interactive chemistry simulations. In: Suits J, Sanger MJ (eds) Pedagogic roles of animations and simulations in chemistry courses. American Chemical Society, Washington, D.C., pp 97-126

Liu H-C, Andre T, Greenbowe T, Liu H-C, Andre T, Greenbowe $\mathrm{T}$ (2008) The impact of learner's prior knowledge on their use of chemistry computer simulations: a case study. J Sci Educ Technol 17(5):466-482

Liu X, Lesniak K (2006) Progression in children's understanding of the matter concept from elementary to high school. J Res Sci Teach 43(3):320-347

Marx JD, Cummings K (2007) Normalized change. Am J Phys 75(1):87-91

Mayer RE, Anderson RB (1991) Animations need narrations: an experimental test of a dual-coding hypothesis. J Educ Psychol 83(4):484-490

Mayer RE, Anderson RB (1992) The instructive animation: helping students build connections between words and pictures in multimedia learning. J Educ Psychol 84(4):444-452

Mayer RE, Moreno R (1998) A split-attention effect in multimedia learning: evidence for dual processing systems in working memory. J Educ Psychol 90(2):312-320

Mayer RE, Sims VK (1994) For whom is a picture worth a thousand words? Extensions of a dual-coding theory of multimedia learning. J Educ Psychol 86(3):389-401

Miles MB, Huberman AM (1994) Qualitative data analysis: an expanded sourcebook, 2nd edn. Sage Publications, Thousand Oaks, CA

Naah BM, Sanger MJ (2012) Student misconceptions in writing balanced equations for dissolving ionic compounds in water. Chemistry Education Research and Practice 13(3):186-194

Naah BM, Sanger MJ (2013) Investigating students' understanding of the dissolving process. J Sci Educ Technol 22(2):103-112

Nurrenbern SC, Pickering M (1987) Concept learning versus problem solving: is there a difference? J Chem Educ 64(6):508-510

Özmen H, Demircioğlu H, Demircioğlu G (2009) The effects of conceptual change texts accompanied with animations on overcoming 11th grade students' alternative conceptions of chemical bonding. Comput Educ 52(3):681-695

Paivio A (1991) Dual coding theory: retrospect and current status. Canadian Journal of Psychology/Revue canadienne de psychologie 45(3):255-287

PhET Interactive Simulations. (2016). Sugar and salt solutions PhET simulation. Retrieved from http://phet.colorado. edu/en/simulation/sugar-and-salt-solutions

PHET Screencast Solubility of Ionic Compounds. (2015) Retrieved from h t t p s : / / w w w. y o u t u be.co m/w a t c h? v = z L i 6 HEQQmlc\&amp;amp;list=UUOZh27juAL15wrp935jUMkw 
Robinson WR (2000) A view of the science education research literature: scientific discovery learning with computer simulations. J Chem Educ 77(1):17-18

Rutten N, van Joolingen WR, van der Veen JT (2012) The learning effects of computer simulations in science education. Comput Educ 58: $136-158$

Sanger MJ (2005) Evaluating students' conceptual understanding of balanced equations and stoichiometric ratios using a particulate drawing. J Chem Educ 82(1):131-134

Sanger MJ, Badger SM (2001) Using computer-based visualization strategies to improve students' understanding of molecular polarity and miscibility. J Chem Educ 78(10):1412-1416

Sanger MJ, Brecheisen DM, Hynek BM (2001) Can computer animations affect college biology students' conceptions about diffusion \& osmosis? Am Biol Teach 63(2):104-109

Sanger, M. J., \& Greenbowe, T., J. (2000). Addressing student misconceptions concerning electron flow in aqueous solutions with instruction including computer animations and conceptual change strategies. Int J Sci Educ, 22(5), 521-537.

Schmidt-Weigand F, Kohnert A, Glowalla U (2010) A closer look at split visual attention in system-and self-paced instruction in multimedia learning. Learn Instr 20(2):100-110

Schwartz RA, Milne C, Homer BD, Plass JL (2013) Designing and implementing effective animations and simulations for chemistry learning. In: Suits J, Sanger MJ (eds) Pedagogic roles of animations and simulations in chemistry courses. American Chemical Society, Washington, DC, pp 43-76

Smith KC, Nakhleh MB (2011) University students' conceptions of bonding in melting and dissolving phenomena. Chemistry Education Research and Practice 12(4):398-408

Smith KJ, Metz PA (1996) Evaluating student understanding of solution chemistry through microscopic representations. J Chem Educ 73(3): 233-235

Stieff M, Hegarty M, Deslongchamps G (2011) Identifying representational competence with multi-representational displays. Cogn Instr 29(1):123-145
Strauss A, Corbin J (1990) Basics of qualitative research: grounded theory procedures and techniques. Sage Publications, Newbury Park, CA

Taber KS (2013) Revisiting the chemistry triplet: drawing upon the nature of chemical knowledge and the psychology of learning to inform chemistry education. Chemistry Education Research and Practice 14:156-168

Talanquer V (2011) Macro, submicro, and symbolic: the many faces of the chemistry "triplet". Int J Sci Educ 33(2):179-195

Tang H, Day E, Kendhammer L, Moore JN, Brown SA, Pienta NJ (2016) Eye movement patterns in solving science ordering problems. J Eye Mov Res 9(3):1-13

Tien LT, Teichert MA, Rickey D (2007) Effectiveness of a MORE laboratory module in prompting students to revise their molecular-level ideas about solutions. J Chem Educ 84(1):175-181

Tobii Technology. (2016). Tobii Studio user's manual (Vol. 3.4.5): Tobii AB.

von Glasersfeld E (1993) Questions and answers about radical constructivism. In: Tobin $\mathrm{K}$ (ed) The practice of constructivism in science education. Lawrence Erlbaum Associates, Hillsdale, NJ, pp 22-38

Wiggins GP, McTighe J (2005) Understanding by design, Expanded 2nd edn. Association for Supervision and Curriculum Development, Alexandria, VA

Williamson VM (2014) Teaching chemistry conceptually. In: Devetak I, Glažar SA (eds) Learning with understanding in the chemistry classroom, vol 1. Springer Netherlands, Dordrecht, pp 103-208

Williamson VM, Abraham MR (1995) The effects of computer animation on the particulate mental models of college chemistry students. J Res Sci Teach 32(5):521-534

Wu HK, Krajcik JS, Soloway E (2001) Promoting understanding of chemical representations: students' use of a visualization tool in the classroom. J Res Sci Teach 38(7):821-842

Yezierski EJ, Birk JP (2006) Misconceptions about the particulate nature of matter. Using animations to close the gender gap. J Chem Educ 83(6):954. doi:10.1021/ed083p954 